\title{
Mitral valve repair for functional regurgitation: Do not miss the last piece of the puzzle!
}

\author{
Roberto Lorusso, MD, PhD, and Sandro Gelsomino, $\mathrm{MD}, \mathrm{PhD}$
}

\author{
From the Department of Cardiothoracic Surgery, Heart \& Vascular Centre, Maastricht University Medical Centre \\ (MUMC+), Maastricht, The Netherlands. \\ Disclosures: Authors have nothing to disclose with regard to commercial support. \\ Received for publication May 23, 2017; accepted for publication May 23, 2017; available ahead of print June 23, \\ 2017. \\ Address for reprints: Roberto Lorusso, MD, PhD, Department of Cardiothoracic Surgery, Heart \& Vascular \\ Centre, Cardiovascular Research Institute Maastricht-CARIM, Universiteitssingel 50, 6229 ER Maastricht, \\ The Netherlands (E-mail: roberto.lorusso@mumc.nl). \\ J Thorac Cardiovasc Surg 2017;154:1258-9 \\ $0022-5223 / \$ 36.00$ \\ Copyright (c) 2017 by The American Association for Thoracic Surgery \\ http://dx.doi.org/10.1016/j.jtcvs.2017.05.073
}

To see what is in front of one's nose needs a constant struggle.

\section{- George Orwell}

The complicated bundle of mitral valve, so clearly described from the time of Leonardo da Vinci, ${ }^{1}$ still represents a big challenge for any surgeon, particularly when the treatment of myocardial infarction-related valve dysfunction is concerned.

Thanks to the pioneering works by the Mayo Clinic group, which provided us with a great amount of new insights into anatomic and functional changes occurring in functional mitral regurgitation $(\mathrm{FMR})^{2}$ and triggered a plethora of literature on the matter during the last 2 decades, cardiac surgeons and cardiologists worldwide are now well aware that FMR is not a primary organic valve disease but rather is secondary to continued left ventricular remodeling, leading to posterior papillary muscle displacement and tethered leaflets. ${ }^{3}$ Papillary muscle displacement relative to the mitral annulus (more than its dysfunction) and related to regional wall motion abnormality in the region of its attachment is therefore the FMR key pathophysiologic factor, finally leading to displacement of the coaptation point toward the left ventricular apex referred as to "tenting." Unfortunately, the intricate conundrum is further complicated by complex 3-dimensional dynamic changes occurring in the mitral annulus in patients affected by FMR.

For all these reasons, nobody could really harbor any illusions that a surgical intervention addressing only the annular end and not the tethering by the remodeled ventricle, such as restrictive mitral annuloplasty, would have been the panacea for resolving such a complex disease. In more recent years, several adjunctive subvalvular procedures (papillary relocation, approximation, sling, chordal cutting, etc) have therefore been developed as adjuncts to annuloplasty; however, these techniques are still difficult to standardize and apply. Finally, chordae-sparing mitral valve replacement is back on the stage of FMR treatment of patients. 6,7 annuloplasty.

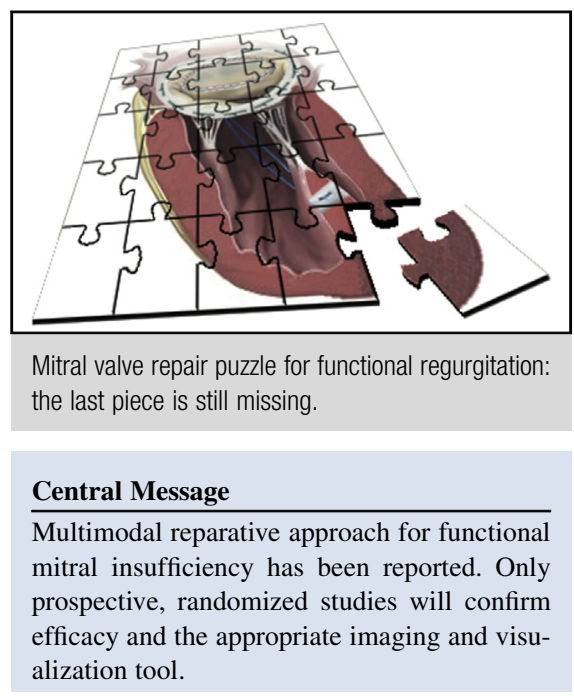

See Article page 1252 .

as a reliable alternative to repair for at least some subgroups

In this intricate scenario, Obase and colleagues ${ }^{8}$ propose in their article in this issue of the Journal a triple repair (3R) approach addressing annulus stabilization, coaptation surface augmentation, and papillary muscle resuspension and provide some clues by comparing, in a few cases, 1-and 5-year freedoms from recurrent mitral regurgitation between standard and 3R approaches, with the latter performing significantly better. The article emphasizes the well-known fundamental role of echocardiography as an invaluable tool for diagnosis, guide to repair, and followup, although this procedure has gained even greater importance for accurate patient selection and guide to a patient-tailored approach. ${ }^{10}$

Data presented appear promising, although the "ventricular problem" is again only indirectly addressed by the $3 \mathrm{R}$ approach, which does not effectively treat the primary ventricular component of FMR. The impression is that we are once more missing the actual last piece of the FMR puzzle. This may be true especially for critically ill patients (more enlarged and spherical ventricles, severe tethering, etc), for whom a surgical strategy addressing the annular dilatation and the concomitant subvalvular dysfunction may not be sufficient. In contrast, patients with limited left ventricular remodeling and dilatation and preserved mitral valve apparatus geometry seem to benefit from isolated mitral ring 
The questions are therefore as follows: Is the $3 R$ approach sufficient for patients in advanced stage of the disease? Instead of such a complex repair, should we not consider a simpler chordae-sparing valve replacement? ${ }^{7}$ This is actually very hard to say, and a multicenter study would provide more meaningful data and objective evidence.

We congratulate the Japanese group, and we look with hope and interest future information from them, eagerly waiting for someone to find the last piece of the puzzle.

\section{References}

1. O'Malley CD, Saunders JB, eds. Ventricles of the heart. In: Leonardo da Vinci: Leonardo on the human body. New York: Dover Publications; 1983:222-56.

2. Yiu SF, Enriquez-Sarano M, Tribouilloy C, Seward JB, Tajik AJ. Determinants of the degree of functional mitral regurgitation in patients with systolic left ventricular dysfunction: a quantitative clinical study. Circulation. 2000;102:1400-6.

3. Piérard LA, Carabello BA. Ischaemic mitral regurgitation: pathophysiology, outcomes and the conundrum of treatment. Eur Heart J. 2010;31:2996-3005.

4. Jensen H, Jensen MO, Smerup MH, Ringgaard S, Sørensen TS, Andersen NT, et al. Three-dimensional assessment of papillary muscle displacement in a porcine model of ischemic mitral regurgitation. J Thorac Cardiovasc Surg. 2010;140:1312-8.

5. Owais K, Montealegre-Gallegos M, Jeganathan J, Matyal R, Khabbaz KR, Mahmood F. Dynamic changes in the ischemic mitral annulus: implication for ring sizing. Ann Card Anaesth. 2016;19:15-9.

6. Lorusso R, Gelsomino S, Vizzardi E, D'Aloia A, De Cicco G, Lucà F, et al; ISTIMIR Investigators. Mitral valve repair or replacement for ischemic mitral regurgitation? The Italian Study on the Treatment of Ischemic Mitra Regurgitation (ISTIMIR). J Thorac Cardiovasc Surg. 2013;145:128-39; discussion 137-8.

7. Acker MA, Parides MK, Perrault LP, Moskowitz AJ, Gelijns AC, Voisine P, et al; CTSN. Mitral-valve repair versus replacement for severe ischemic mitral regurgitation. N Engl J Med. 2014;370:23-32.

8. Obase K, Matsumaru I, Miura T, Eishi K. Echocardiographic visualization and quantification of mitral complex during mitral repair for severe functional mitral regurgitation. J Thorac Cardiovasc Surg. 2017;154: 1252-5.

9. Gelsomino S, van Garsse L, Lucà F, Lorusso R, Cheriex E, Rao CM, et al. Impact of preoperative anterior leaflet tethering on the recurrence of ischemic mitral regurgitation and the lack of left ventricular reverse remodeling after restrictive annuloplasty. J Am Soc Echocardiogr. 2011;24:1365-75.

10. Blossier JD, Bouchard D, Michler RE, Perrault LP. Identifying patients who benefit from restrictive annuloplasty in ischemic mitral regurgitation: an elusive yet essential quest! Toward a patient-tailored approach. J Thorac Cardiovasc Surg. 2016;151:906-8. 